\title{
Knowledge, Attitudes, and Practices with Respect to Epilepsy among Nurses in the City of Niamey, Niger
}

\author{
Hamid Assadeck ${ }^{1,2}$ Moussa Toudou-Daouda ${ }^{1}$ \\ Dijbo Douma-Maiga ${ }^{2,3}$ Samuila Sanoussi ${ }^{4,5}$ \\ 1Department of Neurology, National Hospital of Niamey, \\ Niamey, Niger \\ ${ }^{2}$ Department of Medicine and Medical Specialties, \\ Faculty of Medicine and Pharmacy, Niamey, Niger \\ ${ }^{3}$ Department of Psychiatry, National Hospital of Niamey, \\ Niamey, Niger \\ ${ }^{4}$ Department of Neurosurgery, National Hospital of Niamey, \\ Niamey, Niger \\ ${ }^{5}$ Department of Surgery and Surgical Specialties, \\ Faculty of Medicine and Pharmacy, Abdou, Niger
}

\section{Zakaria Mamadou ${ }^{1}$ Mahadi Moussa-Konate ${ }^{1}$}

J Neurosci Rural Pract:2020;11:454-458

\begin{abstract}
Address for correspondence Moussa Toudou-Daouda, MD, Department of Neurology, National Hospital of Niamey, Niamey, Niger (e-mail: moussatoudou@gmail.com).
\end{abstract}

\begin{abstract}
Keywords

- knowledge

- attitudes

- practices

- epilepsy

- nurses

- Niamey

- Niger
\end{abstract}

Objective The aim of this study is to evaluate knowledge, attitudes, and practices about epilepsy among nurses in the city of Niamey, Niger, to identify existing gaps in their knowledge concerning epilepsy to formulate recommendations to improve the quality of care for people with epilepsy.

Materials and Methods We conducted a descriptive cross-sectional survey on epilepsy knowledge among nurses in the city of Niamey, using a self-administered questionnaire including questions related to knowledge about epilepsy.

Results A total of 98 nurses ( 29 men and 69 women) were included in the survey. The mean age of the participants was of $32.88 \pm 10.87$ years (range: $17-58$ years). The sample consisted of $10.2 \%$ of student nurses, $64.3 \%$ of college patent, and $25.5 \%$ of bachelor nurses. Only $22.4 \%$ of participants reported having heard about epilepsy during their training programs. Among the respondents, $43.9 \%$ of them had already attended at least one epileptic seizure. Epilepsy is considered as a psychiatric illness and contagious disease by 11.2 and $19.4 \%$ of respondents, respectively. The main transmission routes reported were physical contact with an epileptic person (14.3\%) and contact with saliva (4.1\%). Epilepsy was considered as an incurable disease by $5.1 \%$ of respondents. When someone has an epileptic seizure, $10.2 \%$ of respondents think that physical contact with this person should be avoided to prevent from contamination. Only $6.1 \%$ of respondents had appropriate attitudes when someone has an epileptic seizure such as lying the patient on his side, clearing the airway if necessary, and diazepam injection.

Conclusion Considering that people with epilepsy are largely cared out by nurses in Niger, the results of the study justify the need to train nurses with respect to epilepsy to improve their knowledge about epilepsy and the care of people with epilepsy.
DOI https://doi.org/

$10.1055 / \mathrm{s}-0040-1713292$

ISSN 0976-3147.
C2020 Association for Helping Neurosurgical Sick People
License terms

(ㅇ) (1) $\ominus \circledast$ 


\section{Introduction}

The hospital frequency of epilepsy is $29.5 \%$ in Niger and mainly affects men and people younger than 20 years. ${ }^{1}$ In Niger, epilepsy remains a major public health concern, and people with epilepsy experience socioeconomic problems that affect their quality of life more than the disease itself. False beliefs about this condition such as serious, contagious, and incurable illness result in the rejection of the people with epilepsy by the society responsible for social integration problems. ${ }^{2,3}$ A recent study conducted in Niamey, Niger ${ }^{2}$ on knowledge, attitudes, and practices about epilepsy among primary and secondary school teachers found that $38.6 \%$ of teachers considered epilepsy as an impurity, $9.7 \%$ as witchcraft, and $46.2 \%$ as a contagious disease.

In Niger, people with epilepsy are usually cared out by nonphysician health care workers, nonspecialist physicians, and non-neurologist physicians who work mainly in primary and secondary care facilities. Thus, good general knowledge about epilepsy of health care professionals will have a key role in their communication with people with epilepsy and their entourage and therefore could change the public's misconceptions about epilepsy and promote positive attitudes regarding people with epilepsy. Unfortunately, studies have reported among some health care professionals a lack of good knowledge about epilepsy and its problems.4-6

The present study was designed to evaluate knowledge, attitudes, and practices about epilepsy among nurses in the city of Niamey, Niger to identify existing gaps in their knowledge concerning epilepsy to formulate recommendations to improve the quality of care for people with epilepsy.

\section{Materials and Methods}

\section{Study Design and Participants}

Details of the design and protocol have been reported previously. ${ }^{2}$ In brief, we conducted a descriptive crosssectional survey among nurses in the city of Niamey, Niger between June and July 2019 to evaluate their knowledge about epilepsy. There are two categories of nurses in Niger: (1) state-certified nurses who have an education level "baccalaureate +3 years" and (2) basic health workers who have an education level "college patent +3 years." The training modules are very different, and state-certified nurses receive more in-depth training than basic health workers. Overall, these two categories of nurses practice the same activities in hospital settings.

After obtaining their verbal consent, we distribute to nurses questionnaires including questions relating to knowledge about epilepsy that they fill themselves. Each respondent completes the questionnaire alone based on their knowledge about epilepsy without resorting to a colleague to limit the influence of each other in the responses. We recover the completed form when the participant finishes completing the questionnaire.

The study was approved by the Institutional Review Board of the Faculty of Medicine of Abdou Moumouni University of Niamey (Niger) in accordance with the Declaration of Helsinki.

\section{Statistical Analysis}

All statistical analyses were performed using the IBM SPSS statistical software package, version 22.0 (SPSS Inc.; New York, United States). The qualitative variables were expressed as percentages and the quantitative variables as mean \pm standard deviation. The Chi-square test of Pearson and Fisher's exact test was used to compare the proportions of the qualitative variables. The $p$-values $<0.05$ were considered statistically significant.

\section{Results}

\section{Demographic Characteristics of the Participants}

- Table 1 details the demographic characteristics of the 98 nurses who completed the questionnaire. The mean age of the participants was $32.88 \pm 10.87$ years (range: $17-58$ years). Women were more represented with a sex ratio of $2: 4$. The sample consisted of $10.2 \%$ of student nurses, $64.3 \%$ of college patent, and $25.5 \%$ of bachelor nurses.

\section{Knowledge, Attitudes, and Practices about Epilepsy of the Participants}

- Table 2 presents the percentages of responses to questions regarding participants' general knowledge about epilepsy.

Table 1 Demographic characteristics of the participants

\begin{tabular}{|c|c|}
\hline Variables & Number (\%) \\
\hline \multicolumn{2}{|l|}{ Sex } \\
\hline Males & $29(29.6)$ \\
\hline Females & $69(70.4)$ \\
\hline Sex ratio (females/males) & 2.4 \\
\hline \multicolumn{2}{|l|}{ Age (y) } \\
\hline Mean & $32.88 \pm 10.87$ \\
\hline Range & $17-58$ \\
\hline Mean/males & $29.79 \pm 8.12$ \\
\hline Mean/females & $34.17 \pm 11.64$ \\
\hline$<30$ & $43(43.9)$ \\
\hline $30-39$ & $25(25.5)$ \\
\hline $40-49$ & $20(20.4)$ \\
\hline$\geq 50$ & $10(10.2)$ \\
\hline \multicolumn{2}{|l|}{ Profession } \\
\hline Nurses & $98(100)$ \\
\hline \multicolumn{2}{|l|}{ Education level } \\
\hline Student nurses & $10(10.2)$ \\
\hline College patent & $63(64.3)$ \\
\hline Bachelor graduates & $25(25.5)$ \\
\hline \multicolumn{2}{|l|}{ Religion } \\
\hline Islam & $98(100)$ \\
\hline Christianity & 0 \\
\hline
\end{tabular}


Table 2 General knowledge of participants about epilepsy

\begin{tabular}{|c|c|}
\hline Variables & $\begin{array}{l}\text { Number } \\
\text { (\%) }\end{array}$ \\
\hline \multicolumn{2}{|l|}{ Have you ever heard about epilepsy? } \\
\hline Yes & $98(100)$ \\
\hline No & 0 \\
\hline \multicolumn{2}{|l|}{ Who told you about epilepsy? } \\
\hline Friends & $10(10.2)$ \\
\hline Elders (parents and grandparents) & $9(9.2)$ \\
\hline At school during training & $22(22.4)$ \\
\hline Media & $5(5.1)$ \\
\hline I have already attended an epileptic seizure & $43(43.9)$ \\
\hline Parent or relative of an epileptic person & $1(1)$ \\
\hline Nonrespondents & $8(8.2)$ \\
\hline \multicolumn{2}{|c|}{$\begin{array}{l}\text { What do you think is the manifestation of an epileptic seizure? } \\
\text { (more than one answer is allowed) }\end{array}$} \\
\hline Convulsions & $67(68.4)$ \\
\hline Bite of the tongue & $4(4.1)$ \\
\hline Loss of urine & $24(24.4)$ \\
\hline Foaming from the mouth & $25(25.5)$ \\
\hline Loss of consciousness & $28(28.6)$ \\
\hline Behavioral disorders & $13(13.3)$ \\
\hline Do not know & $5(5.1)$ \\
\hline \multicolumn{2}{|c|}{$\begin{array}{l}\text { What do you think is the cause of epilepsy? (more than one } \\
\text { answer is allowed) }\end{array}$} \\
\hline Brain disease & $77(78.6)$ \\
\hline Hereditary disease & $8(8.2)$ \\
\hline Psychiatric illness & $11(11.2)$ \\
\hline Witchcraft & $2(2)$ \\
\hline Possession by geniuses or spirit possession & $9(9.2)$ \\
\hline Insanity & 0 \\
\hline \multicolumn{2}{|l|}{ Do you think that epilepsy is a contagious disease? } \\
\hline Yes & $19(19.4)$ \\
\hline No & $76(77.6)$ \\
\hline Do not know & $3(3.1)$ \\
\hline
\end{tabular}

What do you think is the transmission route for epilepsy? (more than one answer is allowed)

\begin{tabular}{|l|l|}
\hline Contact with the saliva of an epileptic person & $4(4.1)$ \\
\hline Contact with places of crisis & $2(2)$ \\
\hline Breathing the gas emitted during the crisis & $3(3.1)$ \\
\hline Physical contact with an epileptic & $14(14.3)$ \\
\hline By eating foods touched by an epileptic & $2(2)$ \\
\hline Contact with the blood of an epileptic & $1(1)$ \\
\hline \begin{tabular}{l} 
Do you think that epilepsy is a treatable condition? \\
\hline Yes
\end{tabular} & $88(89.8)$ \\
\hline No & $5(5.1)$ \\
\hline Do not know & $5(5.1)$ \\
\hline $\begin{array}{l}\text { How do you think that epilepsy is treated? } \\
\text { (more than one answer is allowed) }\end{array}$ & $78(79.6)$ \\
\hline $\begin{array}{l}\text { Modern medicine } \\
\text { Traditional medicine and or maraboutage }\end{array}$ & $29(29.6)$ \\
\hline $\begin{array}{l}\text { Combination of modern medicine and tradi- } \\
\text { tional medicine and or maraboutage }\end{array}$ & $18(18.4)$ \\
\hline Do not know & $5(5.1)$ \\
\hline
\end{tabular}

Table 3 Attitudes and practices of participants toward epilepsy

\begin{tabular}{|c|c|}
\hline Variables & Number (\%) \\
\hline \multicolumn{2}{|c|}{$\begin{array}{l}\text { What would you do if someone has an epileptic seizure? (here we } \\
\text { present the answers of the participants) }\end{array}$} \\
\hline Call the doctor & $1(1)$ \\
\hline $\begin{array}{l}\text { Calm the seizure by chlorpromazine } \\
\text { injection }\end{array}$ & $3(3.1)$ \\
\hline Calm the seizure by diazepam injection & $30(30.6)$ \\
\hline Calm the seizure by promethazine injection & $2(2)$ \\
\hline $\begin{array}{l}\text { Calm the seizure by diazepam injection and } \\
\text { refer the patient to a hospital }\end{array}$ & $5(5.1)$ \\
\hline $\begin{array}{l}\text { Lying the patient on his side, clearing airway } \\
\text { if necessary, and injecting diazepam }\end{array}$ & $6(6.1)$ \\
\hline Refer the patient to a hospital & $12(12.2)$ \\
\hline Pour water on the patient & $3(3.1)$ \\
\hline Read the Quran & $1(1)$ \\
\hline Do not know & $35(35.7)$ \\
\hline \multicolumn{2}{|c|}{$\begin{array}{l}\text { What will you avoid doing if someone has an epileptic seizure? } \\
\text { (here we present the answers of the participants) }\end{array}$} \\
\hline Abandon the patient & $16(16.3)$ \\
\hline Physical contact with the patient & $10(10.2)$ \\
\hline Make noises around the patient & $9(9.2)$ \\
\hline $\begin{array}{l}\text { Do not leave dangerous objects around the } \\
\text { patient }\end{array}$ & $3(3.1)$ \\
\hline Contact with the places of the crisis & $2(2)$ \\
\hline Do not know & $58(59.2)$ \\
\hline
\end{tabular}

A total of 22 participants (22.4\%) reported having heard about epilepsy during their training programs. Among the respondents, $43.9 \%$ of them had already attended at least one epileptic seizure. Epilepsy is considered as a psychiatric illness and contagious disease by 11.2 and $19.4 \%$ of respondents, respectively. A total of 29 respondents (29.6\%) think that epilepsy is treatable by traditional medicine and or maraboutage, while 78 (79.6\%) think of the treatment by modern medicine. Total 18 participants (18.4\%) think that epilepsy is treatable by the combination of modern medicine and traditional medicine and or maraboutage.

The attitudes and practices of the participants were presented in - Table 3. Total 35 participants (35.7\%) said that they did not know what to do when someone has an epileptic seizure. However, $5.1 \%$ of respondents reported inappropriate attitudes such as "calm the seizure by chlorpromazine or promethazine injection." Only $6.1 \%$ of respondents had appropriate attitudes when someone has an epileptic seizure such as "lying the patient on his side, clearing the airway if necessary, and diazepam injection." Ten participants (10.2\%) think that physical contact with the epileptic person should be avoided to prevent from contamination when this person has an epileptic seizure.

Significantly, nurses aged $<30$ years $(p=0.048)$ and student nurses ( $p=0.035$ ) think that epilepsy is transmitted when you breathe the gas emitted during the seizure ( - Table 4 ). Student nurses believe that epilepsy is a contagious disease but without significance $(p=0.082)$. 
Table 4 Knowledge about epilepsy of the participants by age group and education level

\begin{tabular}{|c|c|c|c|c|c|c|c|c|c|}
\hline \multirow[t]{2}{*}{ Variables } & \multicolumn{5}{|l|}{ Age group } & \multicolumn{4}{|c|}{ Education level } \\
\hline & $\begin{array}{l}<30 \\
(n=43)\end{array}$ & $\begin{array}{l}30-39 \\
(n=25)\end{array}$ & $\begin{array}{l}40-49 \\
(n=20)\end{array}$ & $\begin{array}{l}>50 \\
(n=10)\end{array}$ & P-value & $\begin{array}{l}\text { Student } \\
\text { nurses } \\
(n=10)\end{array}$ & $\begin{array}{l}\text { College } \\
\text { patent } \\
(n=63)\end{array}$ & $\begin{array}{l}\text { Bachelor } \\
\text { graduates } \\
(n=25)\end{array}$ & $p$-Value \\
\hline Psychiatric illness & $6(14 \%)$ & $1(4 \%)$ & $3(15 \%)$ & $1(10 \%)$ & 0.837 & $1(10 \%)$ & $9(14.3 \%)$ & $1(4 \%)$ & 0.353 \\
\hline Brain disease & $33(77 \%)$ & $21(84 \%)$ & $15(75 \%)$ & $8(80 \%)$ & 0.942 & $7(70 \%)$ & $49(77.8 \%)$ & $21(84 \%)$ & 0.590 \\
\hline Hereditary disease & $6(14 \%)$ & $1(4 \%)$ & 0 & $1(10 \%)$ & 0.207 & $2(20 \%)$ & $5(7.9 \%)$ & $1(4 \%)$ & 0.070 \\
\hline Witchcraft & 0 & $2(8 \%)$ & 0 & 0 & 0.986 & 0 & 0 & $2(8 \%)$ & 0.399 \\
\hline Possession by geniuses & $4(9.3 \%)$ & $1(4 \%)$ & $2(10 \%)$ & $2(20 \%)$ & 0.476 & $1(10 \%)$ & $7(11.1 \%)$ & $1(4 \%)$ & 0.210 \\
\hline $\begin{array}{l}\text { Is epilepsy a contagious } \\
\text { disease? }\end{array}$ & $10(23.2 \%)$ & $3(12 \%)$ & $4(20 \%)$ & $2(20 \%)$ & 0.439 & $4(40 \%)$ & $12(19 \%)$ & $3(12 \%)$ & 0.082 \\
\hline $\begin{array}{l}\text { Contact with the saliva } \\
\text { of an epileptic }\end{array}$ & $3(7 \%)$ & $1(4 \%)$ & 0 & 0 & 0.068 & $2(20 \%)$ & $1(1.6 \%)$ & $1(4 \%)$ & 0.161 \\
\hline $\begin{array}{l}\text { Contact with places of } \\
\text { crisis }\end{array}$ & $2(4.6 \%)$ & 0 & 0 & 0 & 0.080 & $1(10 \%)$ & $1(1.6 \%)$ & 0 & 0.154 \\
\hline $\begin{array}{l}\text { Breathing the gas emit- } \\
\text { ted during the crisis }\end{array}$ & $3(7 \%)$ & 0 & 0 & 0 & 0.048 & $2(20 \%)$ & $1(1.6 \%)$ & 0 & 0.035 \\
\hline $\begin{array}{l}\text { Physical contact with an } \\
\text { epileptic }\end{array}$ & $6(14 \%)$ & $3(12 \%)$ & $2(10)$ & $2(20)$ & 0.871 & $2(20 \%)$ & $9(14.3 \%)$ & $3(12 \%)$ & 0.465 \\
\hline $\begin{array}{l}\text { By eating foods touched } \\
\text { by an epileptic }\end{array}$ & $1(2.3 \%)$ & 0 & $1(5 \%)$ & 0 & 0.377 & $1(10)$ & $1(1.6 \%)$ & 0 & 0.154 \\
\hline $\begin{array}{l}\text { Is epilepsy a curable } \\
\text { disease? }\end{array}$ & $38(88.4 \%)$ & 22 (88\%) & 18 (90\%) & $10(100 \%)$ & 0.471 & $10(100 \%)$ & $56(88.9)$ & $22(88 \%)$ & 0.328 \\
\hline Modern medicine & $32(74.4 \%)$ & $20(80 \%)$ & 17 (85\%) & $9(90 \%)$ & 0.258 & $8(80 \%)$ & $50(79.4 \%)$ & $20(80 \%)$ & 0.706 \\
\hline $\begin{array}{l}\text { Traditional medicine and } \\
\text { or maraboutage }\end{array}$ & $13(30.2 \%)$ & $6(24 \%)$ & $8(40 \%)$ & $2(20)$ & 0.893 & $3(30 \%)$ & $20(31.7)$ & $6(24 \%)$ & 0.385 \\
\hline
\end{tabular}

The $p$-value was calculated using Fisher's exact test.

\section{Discussion}

In this descriptive cross-sectional study, we evaluated knowledge about epilepsy among nurses in the city of Niamey, Niger. Because in Niger, people with epilepsy are usually cared out by nonphysician health care workers and nonspecialist physicians, we have chosen to specifically survey nurses in the city of Niamey to evaluate their knowledge about epilepsy to identify existing gaps to make recommendations to introduce detailed information modules regarding epilepsy into the nurses training program. However, the study findings revealed misperceptions and erroneous beliefs about epilepsy in some nurses. Epilepsy is considered as a psychiatric illness and contagious disease by 11.2 and $19.4 \%$ of respondents, respectively. These results confirm the literature data on the lack of good knowledge about epilepsy and its problems among some health care professionals..$^{4-6}$ In our study, $9.2 \%$ of respondents considered epilepsy as a disease due to possession by geniuses or spirit possession. Similar results (10.5\%) were reported in a Saudi Arabian study. ${ }^{3}$ Religious and sociocultural beliefs play an important role in the misperception and erroneous beliefs about epilepsy among some health care professionals who do not have good knowledge about this disease. In the present study, $10.2 \%$ of respondents think that physical contact with the epileptic person should be avoided to prevent from contamination when this person has an epileptic seizure. This attitude seems dangerous because these nurses will not be able to help an epileptic person at the time of the seizure and at the right time. We found, in the present study, $29.6 \%$ of participants suggesting treatment by traditional medicine and or maraboutage, and $18.4 \%$ treatment by the combination of modern medicine and traditional medicine and or maraboutage. Religious and sociocultural beliefs greatly influenced the response of participants in the choice of treatment method. Thus, for some respondents, traditional medicine is the most suitable and effective treatment for epilepsy.

Although $43.9 \%$ of respondents had already attended at least one epileptic seizure, only $6.1 \%$ of respondents had appropriate attitudes when someone has an epileptic seizure such as "lying the patient on his side, clearing the airway if necessary, and diazepam injection." In a Zambian study, 92.6\% of respondents recommended lying the patient on his side. ${ }^{4}$ However, $58.8 \%$ of respondents in this same study recommended putting something hard in the mouth of the patient, which is an inappropriate attitude. We recorded in our study inappropriate attitudes in $5.1 \%$ of cases such as calm the seizure by chlorpromazine or promethazine injection. Besides, $12.2 \%$ of the respondents believe that the patient must be immediately transferred to a hospital as soon as he has an epileptic seizure without thinking about doing initial care. 
These attitudes demonstrate a low level of knowledge about epilepsy and its problems among some nurses in Niger.

In the majority of cases, respondents declare that they did not receive detailed information or formal instructions on epilepsy during their training. Some respondents declared that they received practical information on epilepsy in the workplace with physicians. Almost all of the respondents had shown their satisfaction with the information provided to them regarding epilepsy, and they underlined that continued medical training on this condition is necessary for nurses already in post. This initiative of continued medical training for nurses already in post and integration of detailed information modules on epilepsy in the training modules for future nurses must be heard by the responsible for training nurses and those of the Ministry of Health.

Our study has some limitations. First, this study included only nurses working in the public sectors of the city of Niamey. Second, the narrowness of the sample studied due to a large number of nurses not wishing to participate in the survey. Thus, the generalization of our findings may be limited.

\section{Conclusion and Recommendations}

The study shows misperception and erroneous beliefs and inappropriate attitudes about epilepsy among some nurses in Niamey, Niger. Considering that people with epilepsy are largely cared out by nurses in Niger, the study findings justify the need to integrate into the training modules of future nurses' modules of detailed information related to epilepsy to enable them to acquire know-how about epilepsy. It is also necessary to organize continued medical training for nurses already in post.

\section{Conflict of Interest}

None declared.

\section{References}

1 Assadeck H, Toudou Daouda M, Moussa Konate M, et al. Clinical and etiological characteristics of epilepsy in people from Niger: a hospital-based study from a tertiary care referral center of Niamey, Niger. Epilepsia Open 2019;4(2):318-327

2 Assadeck H, Toudou Daouda M, Moussa Konate M, Mamadou Z, Douma Maiga D, Sanoussi S. Knowledge, attitudes, and practices with respect to epilepsy among primary and secondary school teachers in the city of Niamey, Niger. Brain Behav 2020;10(3):e01539

3 Alaqeel A, Alebdi F, Sabbagh AJ. Epilepsy: what do health-care professionals in Riyadh know? Epilepsy Behav 2013;29(1): 234-237

4 Chomba EN, Haworth A, Atadzhanov M, Mbewe E, Birbeck GL. Zambian health care workers' knowledge, attitudes, beliefs, and practices regarding epilepsy. Epilepsy Behav 2007;10(1): 111-119

5 Vancini RL, Benedito-Silva AA, Sousa BS, et al. Knowledge about epilepsy among health professionals: a cross-sectional survey in Sao Paulo, Brazil. BMJ Open 2012;2(2):e000919

6 Locharernkul C, Suwaroporn S, Krongthong W, Limarun C, Arnamwong A. A study of knowledge and attitude improvement on epilepsy among Thai physicians and nurses. J Med Assoc Thai 2010;93(8):875-884 